\begin{tabular}{|c|c|}
\hline $\begin{array}{c}\text { European Association for the } \\
\text { Development of Renewable Energies, Environment } \\
\text { and Power Quality (EA4EPQ) }\end{array}$ & $\begin{array}{c}\text { International Conference on Renewable Energies and Power Quality } \\
\text { (ICREPQ'12) }\end{array}$ \\
& Santiago de Compostela (Spain), 28th to 30th March, 2012
\end{tabular}

\title{
ECONOMIC DISPATCH OF MICROGRIDS
}

\author{
Julio R. Martinez ${ }^{1}$, Eliane A. Fadigas ${ }^{1}$ \\ ${ }^{1}$ University of São Paulo \\ e-mail: julioromel@yahoo.com.br, eliane@pea.usp.br
}

\begin{abstract}
The concept of MicroGrid (MG) has been proposed as a way to solve several problems associated with the integration of small generators in distribution feeders. The ability of $M G$ operates either connected to the main grid or as an island, without the need of a fast and sophisticated central control, allows exploring in large scale, the use of the renewable and nonrenewable electricity generating technologies in the local consumption. However, new solutions are required to become MicroGrids technically secure and reliable as well as economically attractive. This work presents the results of economic dispatch applied to MGs operating as an island and connected to the grid. The optimization algorithm was developed and implemented in Matlab ${ }^{\circledR}$. The profits obtained when MicroGrid operates in Optimal Power Flow (OPF) allow assessing the degree of complexity that the Local Supervisory Controller can achieve without compromising the economic viability of MicroGrid. The controller performance is evaluated by using power flow for various combinations of generation and load.
\end{abstract}

Keywords: MicroGrid, Economic Dispatch, Distributed Generation, Smart Grid, Optimization.

\section{Introduction:}

$\mathrm{F}$ inancial, economic, and regulatory incentives are changing the electricity production and commercialization rules in Brazil and in the rest of the world. As the demand for power quality and the protection of the environment grows in importance, distributed generation (DG) has increased its market share. The DG consists in power-generating units (thermal and/or electric) located close to consumers. Generation units may be conventional or renewable power sources with rated capacity ranging typically between $15 \mathrm{~kW}$ to $10 \mathrm{MW}$ [1]. The DG is considered a good alternative to traditional forms of electricity production, because in contrast to conventional power, which requires large investments, with facilities of enormous size, the DG permits the use of new technologies, small units with reduced dimensions, high efficient, safety, easy to install and operate, well adapted to several types of loads, and therefore, reduced investment risks. [2].
However, the indiscriminate use of small generators spread of to the grid can bring more problems than solutions. Problems related to stability, voltage regulation and conflicts in the coordination of protections have been reported in [1] and [3]. In this context, the concept of MicroGrid (MG) is proposed to solve the innumerous problems associated with the integration of small generators in low voltage distribution feeders (LV). The MG can be defined as a system formed by energy sources, storage, and loads (possibly controllable), managed by a local supervisory controller (LSC) with the ability to operate connected to the grid or as an island [4]. From the point of view of the network, the main advantage is that the MG can be regarded as a manageable entity within the power system, operated as a single aggregated load with the potential to participate in the provision of ancillary services to the utility [5].

Given the economic benefit, a MicroGrid is usually installed by the consumers who control their own electricity production. Since the Utility's Electric Supply prices includes losses, customer services, congestion, and other costs and taxes; the tariffs are too expensive, so that the self-generation becomes a cheaper alternative and the MG it is an emerging one. The cost-effectiveness of an MG system is a function of its appropriate design and management.

A major problem associated with the operation of an MG, connected and not connected to the main grid, is related to the management of the active power produced by each energy source in order to achieve the desired operation objectives (cost minimization, maximization of the reliability and efficiency) while the constraints of the system are maintained.

This task is usually performed by the LSC, at intervals usually of minutes or hours, based on a broad range of information such as: tariff structure, operational limits of the equipments, weather conditions, electricity demand, heat demand, etc. Some of this information is easy and inexpensive to obtain while some are prohibitively expensive or impossible to obtain [6]. Thus, 
the set of information that affect the performance of $\mathrm{MG}$ must be perfectly known and selected in order to become the development of a LSC economically viable.

The objective of this paper is to present the results of economic power dispatch applied to MicroGrids. The profits obtained when MG operates in OPF allow assessing the degree of complexity that the LSC can achieve without compromising the economic viability of MG.

\section{Description of the OPF problem}

The MicroGrid optimization problem is rather similar to the economic dispatch made by the traditional utilities on a large power systems, however, differs in two important points:

- The combined heat and power (CHP) in the MG, requires the joint optimization of both electrical and heat energy.

- The unlimited purchase of electricity from the utility network is usually an option, unless the MG operates off grid.

For a MicroGrid with K-generating units, the OPF problem can be formulated, such as

$$
\begin{gathered}
\text { minimize } f=\sum_{i=1}^{K} f_{i}(x) \\
\text { subject to } P_{L}(x)+P_{D}-P_{E}-\sum_{i=1}^{K} P g_{i}(x)=0 \\
P_{G}+\sum_{i=1}^{K}\left(P r_{i}(x)-P h_{i}\right)=0 \\
x_{\min } \leq x \leq x_{\max }
\end{gathered}
$$

Where $f$ is the objective function, $P_{L}$ represents the active losses in the network distribution, $P_{D}$ represents the total electrical power demanded by loads, $P_{E}$ is the electric power supplied by the electric utility, $P g_{i}$ represents the electric power output of individual units generators, $P_{G}$ is the supplementary heat provided by some type of fuel, $P r_{i}$ represents the individual heat recovery from the generating units, $P h_{i}$ is the individual load heat close to the CHP plant and $x$ represents the state variables of the system (module and angle of voltages at buses).

\section{Objective Function}

If the objective of OPF is to minimize the total cost of energy generated by the sources, therefore, details of the tariff structure must be known. In this paper, two types of tariffs, typically used by the Brazilian utilities, are considered in the analysis: monomial tariff (applied to residential and commercial sectors) and the conventional binomial tariff (applied to the commercial and industrial sectors). The first one, is a charge based on electric energy $(\mathrm{kWh})$ consumed during a period, usually one month. The second one is a rate charged on a demand and energy basis, independently of the period of the day (peak or off-peak) or period of the year (dry or humid) [7]. In this case, the electric bill of the consumers is composed of three components: tariff applied to the energy consumed, tariff applied to the contracted power demand and an amount charged by the surplus of the contracted demand. Thus, the objective function is composed by four sub-objectives: cost of the energy and demand consumed from the grid, cost of fuel consumption to meet the heat loads, cost of fuel consumption to feed the generating energy sources and operation and maintenance cost (O\&M) of the generating units.

The curves of Input-Output (I-O) of the generating units were modeled using a cubic cost function, therefore the optimization problem is characterized mathematically as a problem of nonlinear programming.

A simulation algorithm based on economic dispatch of power systems was developed and implemented in Matlab $\mathbb{R}$ software to estimate the profits when the MG works in OPF. The algorithm uses the "Quasi-Newton line-search method" to make the optimization and calculations of the optimal dispatch of the sources, minimizing the objective function, while the operating voltage limits, capacity of generation and distribution system are respected.

\section{Test Case}

Fig.1 illustrates the architecture of the LV system used for testing. The system is composed of six micro generators connected to three-phase radial overhead feeders $220 / 127$ $\mathrm{V}$ with conductor AWG 3/0 (R1=0336 $\Omega / \mathrm{km} \mathrm{X1=0401}$ $\Omega / \mathrm{km}$ ). The MicroGrid is connected to the network (bus1) through a distribution transformer $13.8 \mathrm{kV} / 220 \mathrm{~V}, 600 \mathrm{kVA}$ $(\mathrm{R}=2 \%, \mathrm{X}=5 \%)$. Feeders A-B-C meet sensitive electric loads, which require own local generation. The nonsensitive loads are fed by the feeder $\mathbf{D}$, which has no own generation. Feeders A-B-C can operate as an island in case of disturbances in the grid.

The MG has four dispatchable sources (one micro turbine, one fuel cell and two internal combustion engines), and two non-dispatchable sources (one photovoltaic panel and one wind turbine). The micro turbine, fuel cell and one of the internal combustion engines (bus 4) use natural gas as fuel and have heat recovery system. The other internal combustion engine (bus 5), uses diesel as fuel and has no heat recovery system. In addition, MG has a gas pipeline to supply the heat loads that are not supplied by the heat recovery of the sources. The non-dispatchable sources were modeled as negative loads. Performance data for 
modelling the cost function of dispatchable sources were obtained from manufacturers' catalogs. [8] [9] [10] [11].

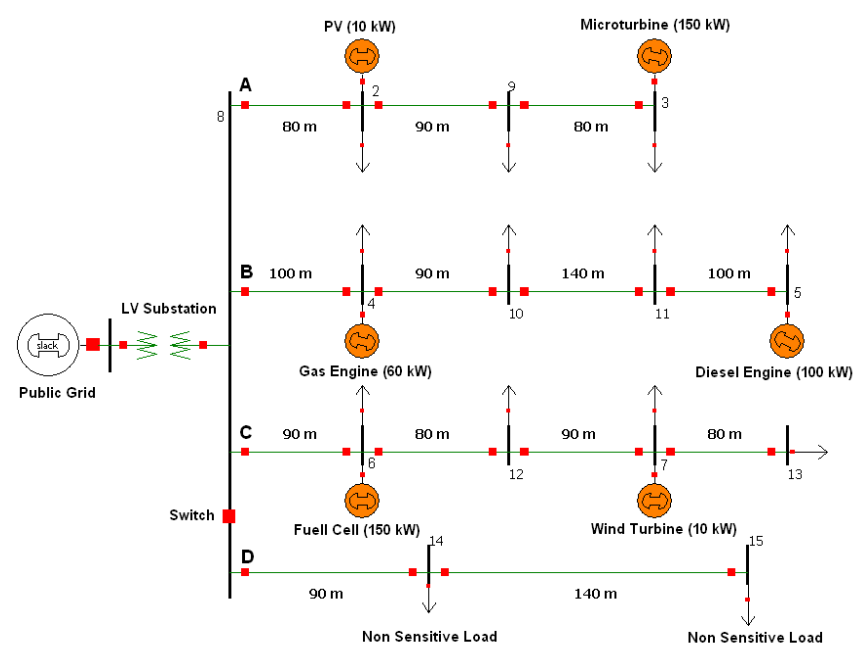

Fig.1 MicroGrid LV test system

We analyzed three levels of electricity demand, whose values are shown in Table 1.

Table 1-Levels of electrical demand

\begin{tabular}{lcc}
\hline \multicolumn{1}{c}{ Level } & $\begin{array}{c}\text { Sensitive Loads } \\
(\mathrm{kW})\end{array}$ & $\begin{array}{c}\text { Non-sensitive } \\
\text { Loads }(\mathrm{kW})\end{array}$ \\
\hline High $(100 \%)$ & 395 & 60 \\
Medium $(75 \%)$ & 296 & 45 \\
Low $(50 \%)$ & 197 & 30 \\
\hline
\end{tabular}

This particular distribution of electrical demand allows to analyze the economic dispatch of $\mathrm{MG}$ both connected to the grid and as an island, since it ensures that when the MG is connected to the grid, own demand is slightly lower than the self-generation (generation=demand + losses), resulting on the possibility of purchasing or not energy from the grid. Otherwise, when the MG is operating as an island and the nonsensitive loads are disconnected of this, the self-generation far exceeds the demand, allowing the economic dispatch of micro generators.

In the case of heat load, it was considered a single load level, whose values are shown in Table 2. These values of heat load correspond to $75 \%$ of the sources recoverable heat when the generator operates at nominal power rating. Utility energy costs, fuel prices and O\&M costs of the units are shown in Table 3. These prices are representative from the city of São Paulo, during 2011.

Table 2 - Location and level of heat Load

\begin{tabular}{cc}
\hline heat Load Location & heat Load (kW) \\
\hline Bus (3) & 214 \\
Bus (4) & 36 \\
Bus (6) & 128 \\
\hline
\end{tabular}

Table 3 - References prices to São Paulo city

\begin{tabular}{lr}
\hline \multicolumn{1}{c}{ Input } & \multicolumn{1}{c}{ Price } \\
\hline Monomial tariff - Energy price (USD/MWh) & 154.47 \\
Binomial tariff - Energy price (USD/MWh) & 94.39 \\
Binomial tariff - Demand price (USD/kW) & 11.72 \\
Binomial tariff - Price of the surplus (USD/kW) & 35.15 \\
Natural Gas (USD/m ${ }^{3}$ ) & 0.76 \\
Oil Diesel (USD/lt) & 1.00 \\
O\&M (USD/kWh) & 0.018 \\
\hline
\end{tabular}

\section{Simulation and Results}

Although the data used on the simulation are real, the simulated scenarios were arbitrary and oriented to examine the performance of an MG when the LSC has an OPF algorithm. Operating costs without OPF were obtained running the micro generators to $100 \%, 75 \%$ and $50 \%$ of its nominal capacity, according to the level of the electrical load analyzed. In this simulation, one-hour time-step is considered and costs are determined assuming that loads and generators set points are constants for each time step.

\section{Scenario 1- Monomial Tariff without Heat Load}

This scenario considers the MG connected to the utility grid. The purchase of electricity is done through a monomial tariff, i.e. not demand charge is considered. MG has no local heat demand. The results are shown in Table 4.

Table 4. Results for Scenario 1

\begin{tabular}{|c|c|c|c|}
\hline Output & $\begin{array}{l}\text { High } \\
\text { Load }\end{array}$ & $\begin{array}{r}\text { Medium } \\
\text { Load }\end{array}$ & $\begin{array}{l}\text { Low } \\
\text { Load }\end{array}$ \\
\hline Grid (kW) & 163 & 74 & 6 \\
\hline Micro turbine $(\mathrm{kW})$ & 75 & 75 & 75 \\
\hline Gas Engine (kW) & 60 & 60 & 18 \\
\hline Diesel Engine (kW) & 54 & 30 & 30 \\
\hline Fuel Cell (kW) & 107 & 101 & 96 \\
\hline Marginal Cost (USD/MWh) & 154.47 & 154.47 & 154.47 \\
\hline OPF Total Cost (USD/h) & 101.13 & 80.08 & 59.12 \\
\hline $\begin{array}{lll}\text { Non-OPF } & \text { Total } & \text { Cost } \\
(\mathrm{USD} / \mathrm{h}) & & \end{array}$ & 12.39 & 88.30 & 64.42 \\
\hline
\end{tabular}

The economic dispatch shows the need to operate the micro turbine at its lower limit, due to the absence of heat loads. The diesel generator also operates at its lower limit. The gas generator and fuel cell are very efficient and operate above their lower limits. It is interesting to note that for the three load levels, the marginal cost of energy equals the rate of electric utility monomial tariff. The maximum savings obtained with $\mathrm{OPF}$ is $\$ 11.26 \mathrm{USD} / \mathrm{h}$, corresponding to the high load.

\section{Scenario 2- Monomial Tariff with Heat Load}

Unlike the first scenario, in this case the MG has a heat load. The electricity tariff applied is the monomial one. The results are shown in Table 5 
Table 5 - Results for Scenario 2

\begin{tabular}{lrrr}
\hline \multicolumn{1}{c}{ Output } & $\begin{array}{r}\text { High } \\
\text { Load }\end{array}$ & $\begin{array}{r}\text { Medium } \\
\text { Load }\end{array}$ & $\begin{array}{r}\text { Low } \\
\text { Load }\end{array}$ \\
\hline Grid (kW) & 108 & 22 & 0 \\
Gas Pipeline (kW) & 0 & 0 & 114 \\
Micro turbine (kW) & 113 & 113 & 75 \\
Gas Engine (kW) & 60 & 60 & 18 \\
Diesel Engine (kW) & 54 & 30 & 30 \\
Fuel Cell (kW) & 125 & 125 & 110 \\
Marginal Cost (USD/MWh) & 152.35 & 125.93 & 84.31 \\
OPF Total Cost (USD/h) & 104.13 & 84.47 & 67.70 \\
Non-OPF Total Cost & 112.39 & 89.46 & 73.32 \\
(USD/h) & & & \\
\hline
\end{tabular}

The difference from Scenario 1 is that the demand for heat makes the Micro turbine, which has a high rate of recovery heat, to be operated near its nominal rated for medium and high electrical load. The diesel generator, which has no recovery of heat, continues to be operated at its lower limit for medium and low electrical load. But the gas generator and fuel cell are operated at rated power for high and medium electrical load. Observe that for low load condition, the economic dispatch shows the need to purchase natural gas to meet the heat loads. The maximum savings obtained with OPF in this case is $\$ 8.26 \mathrm{USD} / \mathrm{h}$, corresponding to the high load.

\section{Scenario 3- Binomial Tariff without Heat Load}

Scenario 3 consists of MG connected to the grid with binomial tariff structure applied. The contracted demand is $25 \%$ of peak demand $(114 \mathrm{~kW})$ for Case A, and 50\% (228 $\mathrm{kW}$ ) for Case B. Charges for surplus demand in the high load condition are taken into account for medium and low demand. MG has no heat demand. The results are shown in Table 6 and 7.

Table 6 - Results for Scenario 3 - Case A

\begin{tabular}{|c|c|c|c|}
\hline Output & $\begin{array}{l}\text { High } \\
\text { Load }\end{array}$ & $\begin{array}{r}\text { Medium } \\
\text { Load } \\
\end{array}$ & $\begin{array}{l}\text { Low } \\
\text { Load }\end{array}$ \\
\hline Grid (kW) & 214 & 148 & 27 \\
\hline Micro turbine (kW) & 75 & 75 & 75 \\
\hline Gas Engine (kW) & 18 & 18 & 18 \\
\hline Diesel Engine (kW) & 57 & 30 & 30 \\
\hline Fuel Cell (kW) & 102 & 77 & 74 \\
\hline Marginal Cost (USD/MWh) & 143.21 & 94.40 & 94.40 \\
\hline OPF Total Cost (USD/h) & 93.25 & 76.58 & 64.87 \\
\hline $\begin{array}{lll}\begin{array}{l}\text { Non-OPF } \\
(\mathrm{USD} / \mathrm{h})\end{array} & \text { Total } & \text { Cost } \\
\end{array}$ & 114.18 & 90.15 & 27 \\
\hline
\end{tabular}

For both values of contracted demand there is a reduction in the final cost of energy, compared to Scenario 1 , for high and medium load regime. Due to the low energy cost of the utility and the absence of heat demand, all sources are operated near their lower limits, even though it means surplus the contracted demand (Case A). It is interesting to note the impact on energy costs as a function of the contracted demand. In this particular case, a contracted demand of $50 \%$ of peak demand has the best economic result than a contracted demand of $25 \%$. The maximum savings obtained with OPF is \$ $20.93 \mathrm{USD} / \mathrm{h}$ (case A), and \$26.42 USD/h (case B), both corresponding to the level of heavy load.

Table 7 - Results for Scenario 3 - Case B

\begin{tabular}{|c|c|c|c|}
\hline Output & $\begin{array}{l}\text { High } \\
\text { Load }\end{array}$ & $\begin{array}{r}\text { Medium } \\
\text { Load }\end{array}$ & $\begin{array}{l}\text { Low } \\
\text { Load }\end{array}$ \\
\hline Grid (kW) & 228 & 148 & 27 \\
\hline Micro turbine $(\mathrm{kW})$ & 75 & 75 & 75 \\
\hline Gas Engine (kW) & 18 & 18 & 18 \\
\hline Diesel Engine (kW) & 53 & 30 & 30 \\
\hline Fuel Cell (kW) & 97 & 77 & 74 \\
\hline Marginal Cost (USD/MWh) & 134.01 & 94.40 & 94.40 \\
\hline OPF Total Cost (USD/h) & 89.62 & 73.51 & 61.80 \\
\hline $\begin{array}{l}\begin{array}{l}\text { Non-OPF } \\
\text { (USD/h) }\end{array} \\
\text { Total }\end{array}$ & 116.04 & 92.00 & 68.12 \\
\hline
\end{tabular}

\section{Scenario 4- Binomial Tariff with Heat Load}

The difference between the Scenario 4 and scenario 3 is that the heat load is now included. The results of Case A and Case B are shown in Tables 8 and 9.

A similar result to scenario 3 is observed at scenario 4. Generated energy costs for high and medium load regime, in both cases, are lower than those observed in scenario 2. Due to the heat demand, the fuel cell operates near its rated power. In contrast, the other sources continue to operate very near to its lower limit.

Table 8 - Results for Scenario 4 - Case A

\begin{tabular}{lrrr}
\hline \multicolumn{1}{c}{ Output } & $\begin{array}{r}\text { High } \\
\text { Load }\end{array}$ & $\begin{array}{r}\text { Medium } \\
\text { Load }\end{array}$ & $\begin{array}{r}\text { Low } \\
\text { Load }\end{array}$ \\
\hline Grid $(\mathrm{kW})$ & 154 & 101 & 0 \\
Gas Pipeline $(\mathrm{kW})$ & 22 & 93 & 114 \\
Micro turbine $(\mathrm{kW})$ & 113 & 75 & 75 \\
Gas Engine $(\mathrm{kW})$ & 18 & 18 & 18 \\
Diesel Engine $(\mathrm{kW})$ & 57 & 30 & 30 \\
Fuel Cell $(\mathrm{kW})$ & 125 & 125 & 110 \\
Marginal Cost (USD/MWh) & 146.61 & 91.75 & 88.15 \\
OPF Total Cost (USD/h) & 98.38 & 82.76 & 71.52 \\
Non-OPF Total Cost & 114.18 & 91.31 & 75.17 \\
(USD/h) & & & \\
\hline
\end{tabular}

Table 9 - Results for Scenario 4 - Case B

\begin{tabular}{lrrr}
\hline \multicolumn{1}{c}{ Output } & $\begin{array}{r}\text { High } \\
\text { Load }\end{array}$ & $\begin{array}{r}\text { Medium } \\
\text { Load }\end{array}$ & $\begin{array}{r}\text { Low } \\
\text { Load }\end{array}$ \\
\hline Grid $(\mathrm{kW})$ & 212 & 101 & $\mathrm{O}$ \\
Gas Pipeline $(\mathrm{kW})$ & 58 & 93 & 115 \\
Micro turbine $(\mathrm{kW})$ & 94 & 75 & 75 \\
Gas Engine $(\mathrm{kW})$ & 18 & 18 & 18 \\
Diesel Engine $(\mathrm{kW})$ & 39 & 30 & 30 \\
Fuel Cell $(\mathrm{kW})$ & 125 & 125 & 110 \\
Marginal Cost (USD/MWh) & 93.12 & 91.75 & 88.14 \\
OPF Total Cost (USD/h) & 97.21 & 82.64 & 71.40 \\
Non-OPF Total Cost & 116.04 & 93.16 & 77.02 \\
(USD/h) & & & \\
\hline
\end{tabular}

The case $\mathrm{B}$ has a better economic result than the case A, for all load levels. To complement the heat demand, is required to purchase natural gas at all load levels. The maximum savings obtained with OPF is $\$$ 
15.80 USD/h (case A), and \$18.83 USD/h (case B), both corresponding to the level of high load.

\section{Scenario 5-MG disconnected from Grid without Heat Load.}

Scenario 5 simulates the operation of MG when it is disconnected from the grid. The results are shown in Table 10 .

Table 10 - Results for Scenario 5

\begin{tabular}{lrrr}
\hline \multicolumn{1}{c}{ Output } & $\begin{array}{r}\text { High } \\
\text { Load }\end{array}$ & $\begin{array}{r}\text { Medium } \\
\text { Load }\end{array}$ & $\begin{array}{r}\text { Low } \\
\text { Load }\end{array}$ \\
\hline Grid (kW) & 0 & 0 & 0 \\
Micro turbine (kW) & 96 & 75 & 75 \\
Gas Engine (kW) & 60 & 60 & 18 \\
Diesel Engine (kW) & 79 & 38 & 30 \\
Fuel Cell (kW) & 150 & 117 & 70 \\
Marginal Cost (USD/MWh) & 236.55 & 191.68 & 83.80 \\
OPF Total Cost (USD/h) & 95.46 & 73.37 & 55.20 \\
Non-OPF Total Cost & 98.06 & 77.32 & 61.24 \\
(USD/h) & & & \\
\hline
\end{tabular}

In the absence of heat load, the micro generators are dispatched according to their efficiency and their penalty factor. The fuel cell and gas generator operate close to the rated capacity, for medium and high electrical demand. The micro turbine and diesel generator operate at its lower limit. In this scenario, the maximum savings obtained with OPF is $\$ 6.04 \mathrm{USD} / \mathrm{h}$, corresponding to low load regime. This result was expected, because under the medium and high load the optimization algorithm is limited by the operating conditions of generators. The marginal cost of energy reaches its maximum value in this scenario, 236.55 USD/MWh.

\section{Scenario 6- MG disconnected from grid with Heat Load}

The difference between Scenario 6 and 5 is that in this case the heat loads are included. The results are shown in Table 11

Table 11 - Results for Scenario 6

\begin{tabular}{lrrr}
\hline \multicolumn{1}{c}{ Output } & $\begin{array}{r}\text { High } \\
\text { Load }\end{array}$ & $\begin{array}{r}\text { Medium } \\
\text { Load }\end{array}$ & $\begin{array}{r}\text { Low } \\
\text { Load }\end{array}$ \\
\hline Grid $(\mathrm{kW})$ & 0 & 0 & 0 \\
Gas Pipeline $(\mathrm{kW})$ & 0 & 22 & 141 \\
Micro turbine $(\mathrm{kW})$ & 113 & 113 & 75 \\
Gas Engine $(\mathrm{kW})$ & 60 & 18 & 18 \\
Diesel Engine $(\mathrm{kW})$ & 73 & 45 & 30 \\
Fuel Cell $(\mathrm{kW})$ & 143 & 125 & 70 \\
Marginal Cost (USD/MWh) & 226.55 & 155.49 & 96.82 \\
OPF Total Cost (USD/h) & 95.91 & 76.86 & 64.99 \\
Non-OPF Total Cost (USD/h) & 98.06 & 82.29 & 67.09 \\
\hline
\end{tabular}

With the need to meet the heat loads, the Micro turbine is now dispatched with its quasi-nominal power, for high and medium load condition. In this case the gas generator, which has a lower rate of heat recovery, shall be operated at its lower limit for medium and low demand. The maximum savings obtained with OPF is $\$ 5.43 \mathrm{USD} / \mathrm{h}$, corresponding to medium load condition. In medium and low load condition there is a need to purchase natural gas to achieve the economic dispatch. Profits with OPF, for all scenarios, are summarized in Fig. 2.

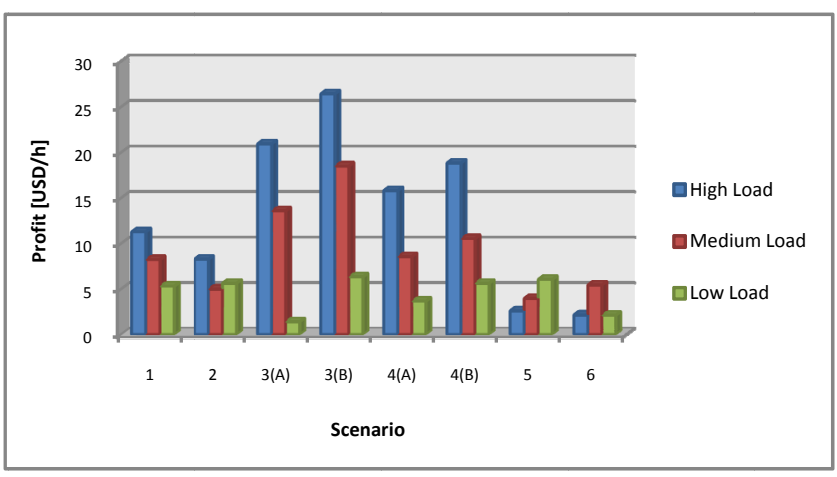

Fig.2 Profit with OPF

The analysis of Fig. 2 shows that the best economic results are achieved for high load regime in all scenarios, except scenario 5 and 6 , according the reasons discussed above. Among all analyzed scenarios, scenario 3 (B) presented the largest decrease in the hourly cost of energy when the OPF algorithm is applied. The purchase of electricity from utility, with binomial tariff structure, consists on the better option for optimizing the system for high and medium load condition, but for low loads, the purchase of energy with monomial tariff is the best economic option. Finally, to estimate the savings obtained by applying the algorithm of OPF, for one-year operation of the MG, it was considered a daily load curve composed of five hours of high demand, 13 hours of medium demand and 6 hours of low demand as shown in Fig. 3. The results are shown in Table 12.

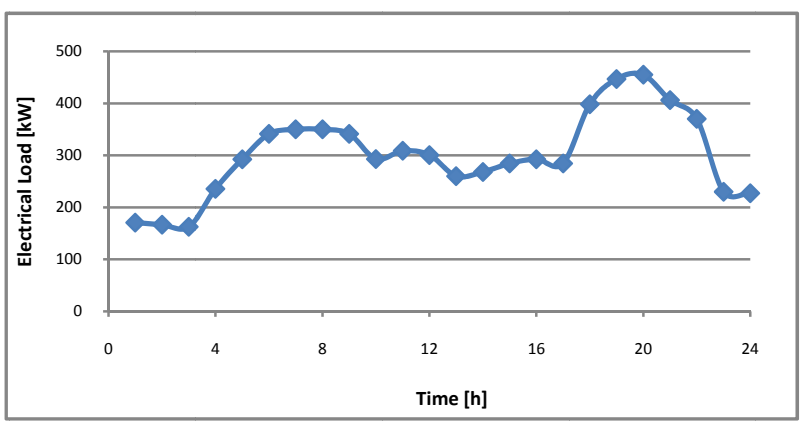

Fig 3. Electricity End-Use Loads for a Week Day

Table 12- Annual Profits with OPF

\begin{tabular}{lr}
\hline Scenarios & Profit [USD/year] \\
\hline Scenario 1 & 71160 \\
\hline Scenario 2 & 51060 \\
Scenario 3 (Case A) & 105653 \\
\hline Scenario 3 (Case B) & 149792 \\
Scenario 4 (Case A) & 77398 \\
Scenario 4 (Case B) & 96590 \\
Scenario 5 & 36715 \\
Scenario 6 & 34288 \\
\hline
\end{tabular}


As expected, the implementation of a LSC with OPF algorithm in Scenario 3 (B), showed the highest annual profit, with approximately $\$ 150,000$ USD per year. The implementation of OPF in Scenario 6 presented the worst result, with a gain of approximately $\$ 35,000$ USD per year. These results allow us to estimate the degree of complexity that the LSC can be achieved without compromising the economic viability of MG. It is also interesting to observe the impact of the OPF algorithm in MGs connected to the grid, especially with binomial tariff structure. In contrast, as an island, MGs, with generating capacity slightly higher than the actual maximum demand, the use of OPF algorithm appears to be unattractive.

\section{Conclusions}

In this work, the economic feasibility of using algorithms for economic dispatch in MicroGrids has been investigated. Only one architecture of MicroGrid, with six possible scenarios of operation was used as a base case for the study. The analysis was based on prices of electricity and fuels in the city of São Paulo, for the year 2011. The results show that under a binomial tariff structure, the use of an OPF algorithm is economically attractive because the MG achieves a better performance if compared to a system without OPF. Stand-alone systems could dispense an OPF algorithm. In this case, micro-generators could be set to run at a specific capacity or could be set to follow loads.

\section{Acknowledgement}

Julio Martinez acknowledges and appreciates receiving scholarships from CAPES (Coordination for the Development of Graduated and Academic Research) of Brazil.

\section{References:}

[1] R.C. Dugan, M.F.McGranaghan, "Eletrical Power Systems Quality”, second edition, McGraw-Hill, 2004.

[2] R. Lasseter, A. Akhil, C. Marnay, "'The CERTS MicroGrid Concept", White paper on Integration of Distributes Energy Resources, April 2002.

[3] T. Niknam, A.M. Ranjbar, A.R.Shirani, "Impact of Distributed Generation on Volt/Var Control in Distribution Networks", IEEE Bologna PowerTech Conference, June 2003.

[4] C. Marnay, G. Venkataramanan, M. Stadler, "Optimal Technology Selection and Operation of CommercialBuilding Microgrids", IEEE Transaction on Power System, 2007.
[5] J.A. Peças Lopes, C.L. Moreira, A.G. Madureira, "Defining Control Strategies for MicroGrids Islanded Operation", IEEE Transactions on Power Systems, Vol 21, No.2, May 2006.

[6] R. Firestone, C. Marnay, "Energy Manager Design for Microgrids", Ernest Orlando Lawrence Berkeley National Laboratory, University of California Berkeley, Jan 2005.

[7] Resolution No. 456, of 29/11/2000, Electrical Energy National Agency - ANEEL.

[8] Capstone Integrated CHP products, available at http://www.microturbine.com, (access July,2010).

[9] Katolight natural gas engines products, available at http://www.katolight.com, (access July,2010).

[10] UTC Power PureCell Systems products, available at http://www.utcpower.com, (access July,2010).

[11] Cummins diesel generator sets products, available at http://www.cummins.com, (access July,2010).

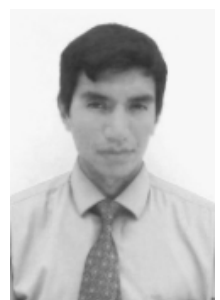

Julio Romel Martinez Bolanos was born in Quito,Ecuador, in 1980. He received the B.S. degree in electrical engineering from the National Polytechnic School (EPN) of Quito, Ecuador, the M.S. degree from the Polytechnic School of the University of São Paulo (USP), Brazil in 2003 and 2008, respectively. He is currently a second year PHD student. His research interests are primarily in stability of autonomous MicroGrids.

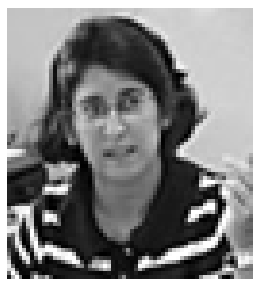

Eliane Aparecida Faria Amaral Fadigas. Received the M.Sc. and $\mathrm{Ph} . \mathrm{D}$ degree in electrical engineering from University of São Paulo (USP), Brazil, in 1993 and 1999 respectively. Since 1996 she is a professor of Electrical Engineering at Polytechnic School of the University of Sao Paulo - BRAZIL. Currently she is the head of Renewable Energy Laboratory at the Electrical Energy and Automation Dept. Her current research activities are concentrated in Power Generation Planning and Alternative Energy Power Generation Systems. 